\title{
“DíA DE MUERTOS” EN OAXACA: MERCANTILIZACIÓN Y FOLKLORIZACIÓN DEL PATRIMONIO CULTURAL
}

"Día de muertos" in Oaxaca: Commodification and Folklorization of Cultural Heritage

\author{
JORGE VALTIERRA ZAMUDIO \\ UNIVERSIDAD LA SALle, MÉXICO \\ jorge.valtierra@lasalle.mx https://orcid.org/0000-0003-3681-7867
}

\author{
RICARDO BERNAL LUGO \\ UNIVERSIDAD LA SALLE, MÉXICO \\ ricardo.bernal@lasalle.mx http://orcid.org/0000-0003-2165-9595
}

RECIBIDO: 31 DE MARZO DE 2020

ACEPTADO: 23 DE JUNIO DE 2020

RESUMEN: En el presente artículo se analiza la idea de patrimonio cultural debido a su relevancia para la materialización de los derechos culturales por parte de los Estados. Con base en los aportes de la antropología y la sociología establecemos una distinción entre una forma de concebir el patrimonio cultural centrada en el folclor y las exigencias del mercado turístico, y otra de carácter más vivencial que subraya la dinamicidad de la cultura, su carácter simbólico y el papel de la memoria. Para ejemplificar esta distinción presentamos algunas ideas surgidas de un ejercicio etnográfico y de observación participante del día de muertos del día 01 al 03 de noviembre de 2018 y 2019, en dos localidades del estado de Oaxaca. Los planteamientos teóricos y los aportes etnográficos nos llevan a subrayar la importancia de tener una concepción más amplia del patrimonio cultural para evitar que los derechos culturales sean reducidos al folclor y a objetos mercantiles.

Palabras ClaVE: Derechos Culturales; Patrimonio Cultural; Folclorización; Mercantilización; Oaxaca

ABSTRACT: This article analyzes the notion of cultural heritage due to its relevance to the materialization of cultural rights by States. Based on the contributions of anthropology and sociology, we establish a distinction between a way of conceiving cultural heritage focused on folklore and the demands of the tourist market and another of a more experiential nature that highlights the dynamism of culture, its symbolic character and the role of memory. To exemplify this distinction, we present some ideas that emerged from an ethnographic exercise and participant observation of the Día de muertos between November 01 to 03, 2018 and 2019, in two locations in the state of Oaxaca. Theoretical approaches and ethnographic contributions lead us to highlight the importance of having a broader conception of cultural heritage to prevent cultural rights from being reduced to folklore and commercial objects.

KEYWORDs: Cultural Rights, Cultural Heritage, Folclorization, Commodification, Oaxaca. 


\section{INTRODUCCIÓN 1}

En la primera década del siglo XXI el tema de los derechos culturales fue motivo de amplios debates en la academia, la sociedad civil y los organismos nacionales e internacionales. Como resultado de estos debates en 2007 apareció la Declaración de Friburgo en la que se reconoce el carácter esencial de los derechos culturales para la dignidad humana y se asume la dimensión cultural de todos los derechos humanos hasta ahora reconocidos (Declaración de Friburgo, 2007). A pesar de que en el Artículo 27 de la Declaración Universal de los Derechos Humanos de Naciones Unidas, promulgada en 1948, ya se reconocía el derecho de toda persona a participar de la vida cultural y aun cuando en el Pacto Internacional de Derechos Económicos, Sociales y Culturales (PIDESC) de 1966 se ratificaba este derecho, la Declaración de Friburgo fue uno de los primeros esfuerzos articulados para clarificar su contenido y concretar legislaciones en la materia.

No obstante, como afirman Lasso, Prado y Giraldo (2019), más de una década después de la aparición de esta Declaración los Estados siguen encontrando dificultades para pasar del reconocimiento formal de los derechos culturales a su materialización e incluso, en los casos en que se han plasmado en las legislaciones nacionales, cabe preguntarse si el enfoque adoptado y las políticas públicas a las que han dado lugar responden a la complejidad de un fenómeno como la cultura. De hecho, parte de la dificultad para "aterrizar" los derechos culturales tiene que ver con las múltiples interpretaciones que se encuentran en juego cuando se habla de cultura y con las confusiones a las que este concepto puede dar lugar.

Ante esta circunstancia, en 2009 se aprobó la Observación General número 21 al Art. 15. 1a del Pacto Internacional de Derechos Económicos, Sociales y Culturales (PIDESC), en la que se intenta aterrizar el contenido de los derechos culturales con la finalidad de otorgar herramientas para su implementación (PIDESC, 2012: 14). Entre otras aportaciones importantes la Observación General número 21 insiste en que el Artículo 15 del PIDESC utiliza el concepto de "vida cultural" con lo que se subraya la dimensión dinámica, evolutiva e histórica de la cultura. De igual forma, en la Observación se argumenta que el derecho a la participación de la vida cultural tiene el carácter de una libertad, por lo que representa, por un lado, una obligación de no injerencia por parte del Estado respecto a las prácticas culturales y el acceso a los bienes culturales y, por otro, medidas positivas orientadas a asegurar "que existan las condiciones previas para participar en la vida cultural, promoverla y facilitarla y dar acceso a los bienes culturales y preservarlos" (CDESC, 1992).

Aunque, en principio, estos elementos favorecen una interpretación amplia que rechaza perspectivas unilaterales de la cultura o la idea de que ésta puede reducirse a un conjunto de elementos particulares definidos por el Estado, en los hechos las políticas culturales adoptadas por las instituciones de gobierno suelen enfocarse cada vez más en el fomento, resguardo y promoción de actividades, espacios, festividades o tradiciones que resultan rentables para el

\footnotetext{
1 El presente artículo es producto de una investigación financiada por el Programa para el Desarrollo Profesional Docente, Tipo Superior (PRODEP). Anexo 511-6/17-7522; julio 2017-diciembre 2018, Dirección Superior Académica, Secretaría de Educación Pública (SEP), con el proyecto "Documentación y Acervo del patrimonio sociocultural en la Sierra Norte de Oaxaca: perspectivas histórico-discursivas y etnográficas".
} 
mercado, generando procesos selectivos que excluyen a grupos enteros y profundizan la invisibilización de manifestaciones y expresiones culturales.

Esto es particularmente evidente cuando se observan los criterios adoptados para definir el patrimonio cultural tangible o intangible, en los que frecuentemente las consideraciones mercantiles y la reducción de la cultura al folclor se han vuelto dominantes. A pesar de que en los discursos institucionales el tema del patrimonio cultural se asocia con el reconocimiento de prácticas rituales y artesanales, danza y diversidad lingüística con el fin de subrayar el gran valor de las minorías étnicas frente a la sociedad dominante y hegemónica, y con ello promover una transformación ideológica del Estado en pos de la diversidad cultural; en la práctica sólo adquieren atención aquellas dinámicas culturales que se adaptan a las exigencias del mercado turístico.

Ante esta tensión entre el reconocimiento de los derechos culturales y la adopción e implementación de políticas y programas que favorecen procesos selectivos basados en los criterios de mercado, los trabajos realizados desde áreas como la antropología social, gestión cultural y sociología ${ }^{2}$ son cruciales, ya que la interlocución permanente con los agentes culturales permite mostrar la complejidad de la cultura y sus manifestaciones materiales y no materiales como el trabajo artesanal, ritualidad, festividades, gastronomía, entre otros. Una comprensión más amplia de los fenómenos culturales puede brindar elementos para que los avances obtenidos al impulsar el reconocimiento de los derechos culturales a nivel institucional, no terminen traduciéndose en políticas que reproducen concepciones selectivas de la cultura.

En este contexto, presentamos un trabajo de antropología social realizado en el estado de Oaxaca, México, famoso por su diversidad cultural. No obstante, en los últimos años se han acentuado prácticas selectivas y/o de exclusión cultural e identitaria. De la mano de distintas instancias gubernamentales se ha generado un entorno en el que predomina una suerte de maquinaria de folclorización que obedece y satisface un mercado turístico que coexiste con manifestaciones socioculturales, la mayor de las veces invisibilizadas.

Con base en algunos resultados de un ejercicio etnográfico y observación participante del Día de Muertos y Todos Santos los días 01, 02 y 03 de noviembre de 2018 y 2019, en dos colonias o barrios al interior de la ciudad de Oaxaca, así como en una población a las afueras de ésta de filiación zapoteca, se ha recabado información sobre la vivencia cultural de los habitantes de estas localidades. Entre otras cosas, el ejercicio da cuenta de los mecanismos de folclorización, (re)interpretación y selectividad de los rasgos culturales, circunstancia que nos obliga a repensar cómo es que los Estados, en particular el mexicano, han "aterrizado" los derechos culturales reconocidos en su legislación.

Para ello, en primer lugar, se harán explícitos los problemas generados al adoptar una perspectiva folclórica de la cultura que se contrapone a la vivencia y praxis del patrimonio local tomando como referencia los planteamientos que realiza Llorenç Prats (2005) desde un posicionamiento socioantropológico y de forma crítica. Posteriormente, se presentarán algunos

\footnotetext{
2 Desde nuestra perspectiva, disciplinas como la antropología social, la sociología, la conservación, la gestión cultural, entre otras, nos proveen de un repertorio conceptual surgido de las vivencias, el contacto con los actores o agentes culturales en su cotidianidad, y los productos y manifestación de su cultura (bienes culturales).
} 
casos con base en la información etnográfica obtenida en noviembre de 2018 y 2019 en la ciudad de Oaxaca - en específico de un barrio con gran afluencia turística como el de Xochimilco y de la agencia de Cinco Señores en la ciudad con características más populares, así como del poblado zapoteco de San Antonino Castillo Velasco, perteneciente al distrito de Ocotlán del Valle- a través de los que se da un mayor sustento al debate desarrollado en torno a los derechos culturales y el patrimonio cultural.

Por último, se enfatiza la importancia de fortalecer y hacer visibles los rasgos culturales, no sólo para reducir las formas veladas de exclusión cultural provocadas por las prácticas culturales folclorizadas, sino también para generar mecanismos y herramientas orientadas al fortalecimiento cultural y, con éste, a la cohesión social de ciertas minorías étnicas.

\section{CULTURA Y PATRIMONIO CULTURAL}

El término de cultura es un término complejo que puede ser abordado desde distintas perspectivas, dependiendo del enfoque teórico y del ámbito disciplinar del que se parta. ${ }^{3}$ Aunque no es el objetivo de este artículo adentrarnos en estos debates, sí consideramos necesario rechazar aquellos acercamientos que reducen la cultura a un conjunto de objetos o prácticas exclusivas de algunos grupos sociales ${ }^{4}$ o definidos por ciertas instituciones. Esto es importante porque estas definiciones tienden a influir en aquello que se considera patrimonio cultural y aquello que queda fuera de esta categoría.

A pesar de sus dificultades, la concepción de cultura de Terry Eagleton es un buen punto de arranque para evitar cualquier perspectiva reduccionista de este fenómeno. Al referirse a la cultura Eagleton (2018) incluye elementos esenciales como valores, costumbres y creencias que los seres humanos individual y colectivamente expresan para sí y entre ellos, subrayando lo que él denomina práctica simbólica y no sólo “expresión simbólica” como Geertz (1987).

En efecto, las actividades, hábitos y normas se traducen en una forma específica de concebir la realidad que diferencia una sociedad de otra e incluso a un individuo de otro. Esta suerte de cosmovisión supone códigos y/o propiedades simbólicas que se van heredando de generación en generación. De ahí que la cultura también posea una dimensión temporal a la que podemos denominar memoria. A la expresión o manifestación tangible e intangible de estos elementos que constituyen la cultura (símbolos, praxis y memoria) se le llama patrimonio (Castellanos-Arenas, 2014).

\footnotetext{
${ }^{3}$ En la actualidad, aún no se observa de forma consensuada qué es la cultura y esto obedece, en parte, a la diversidad de disciplinas y corrientes ideológicas que intervienen para definirla. Son muchos y diversos autores los que han buscado explicarla como Claude Levi-Strauss, Marvin Harris, Clifford Geertz, entre otros. Este último alude a la expresión simbólica de la sociedad (Geertz, 1987: 24). Así, desde el momento en que la cultura implica varias pautas de significados que manifiesta una forma de ser social (Lizama, 2006), la definición de Eagleton es adecuada, toda vez que se refiere a una buena cantidad de características de las que destaca la cuestión simbólica que es vital para comprender la cultura, su dinámica y significado.

${ }^{4}$ De hecho, algo común en México es utilizar expresiones como 'ser inculto' cuando se alude a alguien que, por distintas condiciones socioeconómicas, educativas, ideológico-religiosas o políticas, incluso lingüísticas como la manera en que se hace uso del castellano o cómo se pronuncia, definen a un individuo o grupo social de forma peyorativa. La exclusión se manifiesta a partir de esta definición como aquel que carece de cultura.
} 
Esta concepción del patrimonio cultural contrasta con definiciones y perspectivas de instituciones internacionales y de organismos gubernamentales y no gubernamentales internacionales y nacionales que tienden a seleccionar y clasifican lo que debe o no ser entendido como patrimonio cultural. En más de una ocasión estos criterios terminan por cosificar la cultura y su expresión, como ocurre con la UNESCO que define el patrimonio cultural como aquello que:

[...] comprende las obras de sus artistas, arquitectos, músicos, escritores y sabios, así como las creaciones anónimas surgidas del alma popular y el conjunto de valores que dan sentido a la vida. Es decir, las obras materiales y no materiales que expresan la creatividad de ese pueblo: la lengua, los ritos, las creencias, los lugares y monumentos históricos, la literatura, las obras de arte y los archivos y bibliotecas (Bazante, 2008: 14).

Aunque en esta definición de patrimonio se incluyen las creaciones que forman parte de la expresión de la identidad de un pueblo o sociedad pueden localizarse al menos tres problemas. Por un lado, la idea de anonimato implica no reconocer la autoría de los individuos y la colectividad cultural. Por otro lado, prevalece la idea de una cultura concentrada en obras de arte, archivos, monumentos, entre otros elementos, sin reconocer las prácticas cotidianas per se y las relaciones sociales que éstas conllevan, o prácticas que son sólo visibles para la localidad y no para un ámbito más global. Por último, no se menciona ni se observa la importancia de las prácticas simbólicas que forman parte de un terreno subjetivo y que implican una interacción comunitaria.

Al no reconocer o identificar características y rasgos culturales locales, cotidianos y simbólicos, la idea de patrimonio cultural resulta insuficiente, superflua y tiende a generar una práctica selectiva que cosifica la cultura. En más de una ocasión este proceso selectivo, favorece la reducción de la cultura de una comunidad, una región o un pueblo, a una serie de mercancías orientadas a satisfacer un mercado cultural predominantemente turístico. Así se subraya el "carácter cultural" de un sitio arqueológico, de arte pictórico, musical o literario, en detrimento de otras prácticas que no se conciben como expresiones culturales. ${ }^{5}$

El problema de percibir el patrimonio desde estas dimensiones es que más que una memoria que se transmite de generación en generación, el patrimonio tiende a verse como un producto que se suministra. La mercantilización de la cultura corre a la par de un incremento acelerado del turismo que articula a la economía con la sociedad, pero también de una serie de políticas estatales e internacionales que no separa lo cultural del entretenimiento. ${ }^{6}$

Al respecto, retomando las bases de un concepto de Jean y John Comaroff, José Luis Escalona habla sobre la etnomercancía; esto es, "un objeto que tiene la apariencia de ser producto

\footnotetext{
5 A pesar de que se reconocen rasgos culturales como la lengua, los rituales y el conocimiento heredado para una actividad en específico como la producción artesanal, muchos de estos rasgos también son negados, lo que lleva a su desplazamiento y extinción.

${ }^{6}$ Desde luego que esto ocurre por intereses económicos, pero también debido a una enorme ignorancia por parte de algunos funcionarios que detentan cargos en esa área Un ejemplo actual en México es el nombramiento el 27 de septiembre de 2018 hasta la fecha, del diputado Sergio Mayer Mori, un exintegrante de un grupo de música pop (Garibaldi) en la década de 1980, para detentar el cargo de presidente de la comisión de cultura en la Cámara de Diputados.
} 
de una perspectiva cultural específica, resultado de trabajo que supone implica un conocimiento especializado y que expresa formas de entendimiento del mundo que son también específicas de un grupo social" (Escalona, 2016: 261). La idea de etnomercancía como la construcción de un bien mercantil al que se le incorporan deliberadamente aspectos supuestamente culturales, nos permite entender una serie de fenómenos que se concentran en añadir artificialmente valores culturales, reinterpretar la cultura y (re)inventarla, por un lado, en lo que Escalona denomina sobrefetichización de la mercancía ${ }^{7}$ y, por otro, en la idea de tradiciones inventadas a la que alude Hobsbawm y Ranger. ${ }^{8}$

En este tenor, identificamos una tendencia a concebir el patrimonio cultural y los bienes culturales con estos aspectos de reinterpretación, reinvención y sobrefetichización -lo que definiríamos de forma general como una suerte de folclorización. Aunque la tendencia de mercantilizar la cultura a través de su folclorización se da en todo el mundo, ${ }^{9}$ en México iniciativas como los eventos y espectáculos de 'luz y sonido' en sitios arqueológicos, la participación de un público en rituales reinventados y más cercanos al New Age, la restauración en no pocas ocasiones descuidada de inmuebles que dan una suerte de vitalidad a poblaciones enteras para ser 'pueblos mágicos,' entre otras prácticas, desvirtúan y transforman el sentido del patrimonio cultural; reduciéndolo a una mercancía (Rosas Mantecón, 2006).10 Aún más, en tanto que la inversión pública y privada se orienta a estas formas de recreación, incluso reinvención, de la cultura, se alejan de las prácticas concretas de productos o bienes culturales que tienen lugar en la comunidad.

Frente a esta perspectiva reduccionista y selectiva, una concepción amplia del patrimonio cultural debería considerar toda la serie de prácticas y bienes culturales que se realizan por una comunidad o un grupo social aun cuando no sean visibles para el mercado. Aunque es verdad que la cultura se expresa en bienes culturales, no sólo lo hace en bienes mercantiles, sino en muy

\footnotetext{
7 Escalona habla de la sobrefetichización como aquel fenómeno en el que la mercancía (llamada artesanía) en el mercado se les da una apariencia e idea de etnicidad (Escalona, 2016: 277), lo que también podría pensarse en el caso de representaciones intangibles de la cultura como un ritual o una danza.

8 Para Hobsbawm y Ranger la tradición inventada tiene la función de reforzar la identidad y cohesión nacionales, a través de un "conjunto de prácticas normalmente regidas por reglas aceptadas en forma explícita o implícita y de naturaleza ritual o simbólica, que tienen por objeto inculcar determinados valores y normas de conducta a través de su reiteración, lo que automáticamente implica la continuidad con el pasado" (Hobsbawm \& Ranger, 2012: 8).

9 Néstor García Canclini define este proceso como cultura global o globalización cultural (García Canclini, 2006: 60).

10 En México, desde hace varios años (aunque hubo algo similar en la década de 1980) se ha llevado a cabo una iniciativa para el turismo que consiste en presentar música regional o una historia musicalizada acompañada de un juego de luces que se proyecta sobre monumentos históricos (coloniales o sitios arquelógicos). También ha proliferado una serie de eventos como danzas, performances, y se ha invertido en infraestructura en algunas poblaciones para otorgarle "atributos simbólicos, leyendas, historia, hechos trascendentes, cotidianidad, en fin magia que te emanan en cada una de sus manifestaciones socio-culturales, y que significan hoy día una gran oportunidad para el aprovechamiento turístico" (Sectur, 2014), esto con el fin de "revalorar a un conjunto de poblaciones del país que siempre han estado en el imaginario colectivo de la nación en su conjunto” (Sectur, 2014). En la definición y características de los pueblos mágicos desde el Estado es clara la perspectiva folclorizante.
} 
diversas manifestaciones que conllevan un trasfondo intangible vinculado con la memoria colectiva, el espacio y la identidad. ${ }^{11}$

En ese sentido, Llorenç Prats señala que la patrimonialización consiste en una forma de sacralización de la externalidad cultural:

Se trata de un mecanismo universal, intercultural, fácilmente reconocible mediante el cual toda sociedad define un ideal cultural del mundo y de la existencia y todo aquello que no cabe en él o lo contradice, pasa a formar parte de un más allá, que, por su sola existencia delimita y desborda la condición humana, socialmente definida y, por ende, nuestra capacidad de explicar y dominar la realidad (Prats, 2005: 18).

Desde esta perspectiva el patrimonio cultural es más que un bien cultural, pues tiene que ver con los significados, lo simbólico, la memoria, el legado y el reconocimiento de la identidad desde los ámbitos locales, pero también por parte de la sociedad global (González-Varas, 2015). Uno de los errores comunes con respecto a concebir el patrimonio es pensarlo como un contenido único sin cambio alguno a través del tiempo, como una pieza de museo. Ciertamente, la idea que se tiene de patrimonio desde esta noción estática es la que más se ha explotado en las representaciones estatales y en la venta de bienes culturales donde los consumidores buscan experimentar o comprar un fragmento de la cultura, por ejemplo, oaxaqueña, chiapaneca, michoacana, etc. Sin embargo, la cultura, y por lo tanto el patrimonio cultural, es dinámica y en sus transformaciones constantes se reafirma y nutre la identidad cultural.

Como lo señalamos más arriba, la idea de patrimonio cultural es esencial, entre otras cosas, al momento de responder a la pregunta sobre cómo pueden traducirse los derechos culturales. En términos generales podemos afirmar que hay dos maneras de concebirla que dan pie a diferentes políticas gubernamentales y favorecen distintas dinámicas sociales. La primera, hasta ahora hegemónica, podría ser considerada como folclórica y se orienta a la creación de escenarios que satisfacen un nicho principalmente turístico, y, en algunos casos, buscan la identidad nacional a partir de la manifestación de las ideas populares sobre el origen de un pueblo (Stanley, 2000).

La segunda podría considerarse como vivencial y se sostiene en la actividad comunitaria que reproduce sus tradiciones sin un fin necesariamente mercantil. En esta concepción, el patrimonio cultural, en esencia, implica una comprensión de ciertos significados y símbolos de grupos y comunidades que se relacionan íntimamente con su sentimiento de pertenencia, pues éste se concibe como una parte fundamental de su identidad.

Ahora bien, la festividad del Día de Muertos, es particularmente intersante para estudiar la manera en la que se relacionan ambas formas de concebir el patrimonio debido a su propio origen. En efecto, como explica la historiadora Elsa Malvido, se trata de una "fecha que se ha convertido en un lugar común promovido por la industria turística nacional e internacional.

\footnotetext{
${ }^{11}$ Esta idea de patrimonio cultural puede relacionarse con la idea de Walter Benjamin según la cual "[...] incluso a la más perfecta reproducción de una obra de arte le falta algo: su presencia en el tiempo y el espacio, su exigencia única en el lugar en el que está que refiere a la historia a la que estuvo sujeta a lo largo de su existencia. Esto incluye los cambios que pudiera haber sufrido en su condición física con los años, como también los distintos cambios de dueño [...]" (Benjamin, 2015: 30).
} 
Alimentado por intelectuales nacionales y extranjeros que hoy es declarado patrimonio intangible de la humanidad" (Malvido, 2006: 42).12

No obstante, cuando se profundiza en el estudio sobre la muerte, ritos, símbolos y costumbres. distan bastante de lo que se dice en los medios de comunicación, pues es claro que el Día de Muertos en México es un constructo reciente difundido por la intelectualidad mexicana y extranjera en la década de 1930 que tuvo tanto un impacto internacional sin precedentes. En realidad, nos enfrentamos al rescate y recreación tanto de costumbres populares coloniales provenientes del cristianismo, como de otras costumbres paganas románicas, a las que se les asignó un nuevo sentido, a saber de corte prehispánico "fácil de creer y difícil de probar" (Malvido, 2006: 43).

Así, el Día de Muertos es una festividad llevada a cabo por la población en el sentido de un patrimonio cultural vivencial, pero al que se entretejen características folclóricas que han recreado y reinterpretado una costumbre a la que se adjudica un origen ancestral históricamente improbable, por lo que es una forma de tradición inventada con el propósito, como señala Brandes (2000), de buscar una identidad nacional que ha tenido un impacto transfronterizo, lo que ha generado una imagen de México y un pasado glorioso precolombino muy característico para aprovecharse en el enriquecimiento de la oferta turística.

Esto significa que mientras el Día de Muertos es una festividad apropiada por muchas poblaciones mexicanas mestizas e indígenas y llevada a la práctica los días 1 y 2 de noviembre, también es una festividad espectacular folclorizada que se desempeña de forma paralela, incluso entretejida, con la otra. Es por ello que la idea del patrimonio cultural local vivencial y el patrimonio cultural folclórico, pueden analizarse por separado y deben diferenciarse, pero con la conciencia de que ambos están intersectados.

De ahí que durante el Día de Muertos en México, en particular en Oaxaca, puedan encontrarse ambas realidades e incluso otras intermedias. Así, lejos del folclor que recientemente ha reinterpretado esta festividad para hacerla una 'mercancía que se suministra', existe una vivencia alrededor de los signos y símbolos de diferenciación que sustentan la identidad social de los oaxaqueños, con objetos culturales que otorgan valor y representatividad a la población (Lizama, 2006). De esta forma, la fiesta se presta tanto a un momento o evento de esparcimiento atractivo que puede ser aprovechado para rediseñarlo para el turismo; pero también es "un problema simbólico" con "significados, respresentaciones y prácticas a los que la gente se vincula, interactúa entre sí y, a través de ellos, contribuyen simbólicamente la ciudad y dotan de sustentos sus identidades" (Lizama, 2006: 31).

Por lo mismo, una fiesta como el Día de Muertos puede ser entendida como algo apropiado e interiorizado en la población: podemos hablar de un patrimonio cultural vivencial desde el momento en que implica una interacción social en la que se intercambian y expresan símbolos, y

\footnotetext{
12 Brandes define esta festividad como un "término específicamente mexicano que se refiere a la visión mexicana de dos festividades católicas, panromanas: el día de Todos Santos y el de las Ánimas, celebrados respectivamente el 1 y 2 de noviembre. En sentido estricto, ambos días llamados también Día de los Muertos o Día de los Fieles Difuntos, normalmente acaecen el 2 de noviembre [...]" (Brandes, 2000: 8).
} 
donde los actores o habitantes de la localidad usan la fiesta para identificarse como comunidad, pero también para diferenciarse con otras comunidades e incluso entre ellos.

Sin embargo, existe otra cara de la moneda, ya que en algunas de sus manifestaciones también se localizan muchas características de lo que se concebiría como sobrefetichización desde la perspectiva de Escalona y de una tradición inventada hobsbawmiana. Ciertamente, como señalamos arriba, la festividad del Día de muertos fue "reinventada" en siglo XX, no obstante, en las útimas décadas se ha visto sometida a una "nueva reinvención" toralmente orientada al mercado, desde el contexto en el que surge, pasando por el nuevo discurso de la festividad, hasta la manera como se organiza la misma, los objetivos preponderantes son distintos a los de la identidad de la población y tienen que ver más con aspectos económicos.

Finalmente, cabe destacar un tercer escenario en el que tanto folclor como lo vivencial se intersectan. Así como pueden distinguirse caracteríscas espectaculares y sobrefetichizadas en la celebración de Día de Muertos, haciendo de esto una etnomercancía, también los pobladores al margen de estas dinámicas experimentan su tradición heredada de varias generaciones atrás. Un ejemplo muy esclarecedor al respeto es el de Juanita Garcíagodoy, que en el marco de nuestro trabajo etnográfico en el panteón de Xoxocotlán explica la forma en que el espacio de cada tumba en el panteón es ocupado por los familiares del difunto, pero también en ocasiones se presentan turistas extranjeros y nacionales dirigidos y organizados por un guía turístico que los lleva a experimentar el espectáculo en la noche, sólo pidiendo respeto para no interferir en las tumbas donde se encuentran los familiares del finado en convivencia (Garcíagodoy, 1998).

A continuación, se buscará mostrar la manera en la que se hacen presentes ambas concepciones del patrimonio cultural con base en información etnográfica acerca de representaciones simbólicas en comunidades del interior de la ciudad de Oaxaca, así como fuera de ésta, en la población de San Antonino Castillo Velasco, respectivamente. Con ello se pretende mostrar la importancia del simbolismo y la apropiación social, como rasgos que deben asociarse a la definición de patrimonialidad.

\section{LA CULTURA FOLKLÓRICA Y LA CULTURA VIVIDA: UN ANÁLISIS DESDE LA ETNOGRAFÍA EN} OAXACA

En México, uno de los estados que más han explotado la patrimonialidad desde el sector turístico y artesanal ha sido Oaxaca. De hecho, la mayor parte del estado vive de esta práctica económica. ${ }^{13}$ Buena parte de los "eventos culturales" más promocionados como la Guelaguetza en el mes de julio son en realidad reinvenciones de tradiciones multirregionales que llegan a ser atractivas para un público masivo internacional; por lo tanto, suponen un espacio en el que se incorporan diversas áreas de oportunidad económica como la vasta oferta de recorridos a los diversos sitios arqueológicos que hay en la zona como Mitla, Atzompa o Montealbán; visitas a distintos lugares en los que se encuentra una gran variedad gastronómica como en los mercados o restaurantes especializados (comida tradicional o comida fusión); una importante presencia de

\footnotetext{
${ }^{13}$ También incluye la relativamente poca actividad industrial, que se relaciona con estos elementos turísticos como el caso del mezcal, en especial en los Valles Centrales de Oaxaca, que se ha insertado en el sector artesanal, turístico y patrimonial.
} 
casas de artesanías o "arte popular", en donde se ofrecen productos a altos costos como textiles, chocolate, dulces artesanales, vasijas y figuras de cerámica, entre otros, así como gran cantidad de galerías de arte y museos.

En este sentido, el estado de Oaxaca presenta muchos elementos y prácticas culturales que advierten una gran diversidad de regiones, de grupos sociales y lenguas que se manifiestan en los bienes culturales y costumbres — fiestas, gastronomía, danzas, entre otros aspectos-, pero dentro de esa diversidad de rasgos y manifestaciones culturales hay detrás una dinámica familiar, interacción social, prácticas comunitarias y cosmovisión que parecen no ser visibles en la definición del patrimonio, así como elementos que no sólo se hacen visibles, sino se reinventan, superfetichizan o hiperbolizan con un fin económico.

Para los propósitos de este artículo es indispensable mostrar con base en información etnográfica algunos casos que ilustren más el fenómeno de Día de Muertos y sus dimensiones. En particular, se desarrollará a continuación la descripción de eventos o manifestaciones patrimoniales como las comparsas en varios barrios y agencias de la Ciudad de Oaxaca del 1 y 2 de noviembre de 2018 y 2019, y el uso artesanal de la "flor inmortal" del municipio de San Antonino Castillo Velasco el día de responso, el 3 de noviembre de 2018.

\section{EXPRESIONES PATRIMONIALES. EL DÍA DE MUERTOS EN OAXACA}

En este artículo hemos recordado que al menos desde los años treinta la intelectualidad mexicana e internacional ha tenido un papel vital en la reinvención, recreación y folclorización de las festividades en torno a la muerte. Sin embargo, coincidimos con Hiriart quien señala que las últimas décadas del siglo XX se han caracterizado por la presencia de un turismo desmedido lo que ha provocado una explotación comercial en la que se priorizan los festejos triviales masivos (Hiriart, 2006) sobre otras prácticas culturales que son ignoradas por las instituciones que pretenden garantizar y fomentar los derechos culturales.

En el estado de Oaxaca, estas fechas han sido importantes durante décadas para destacar y expresar la identidad de los oaxaqueños. ${ }^{14}$ Sin embargo, el Estado se ha concentrado en un mercado turístico caracterizado por una dinámica de reinvención de las prácticas culturales, por su folclorización y por la mercantilización del patrimonio cultural. Esto puede ejemplificarse con las comparsas oaxaqueñas.

La comparsa es una representación popular en la que el día de los Fieles Difuntos o Día de Muertos, el $1^{\circ}$ de noviembre, mucha gente se disfraza. Generalmente se busca que estos disfraces sean diseñados por ellos mismos y que destaquen motivos tradicionales como la muerte representada con "la catrina", "la llorona", "la planchada", "el charro negro", "el diablo", "la

\footnotetext{
14 Ciertamente, existen algunos de los símbolos nacionales y locales que se relacionan con discursos históricos que fortalecen una identidad local-nacional, como el natalicio del personaje histórico Benito Juárez y lo que la figura del juarismo significa para los oaxaqueños. En otros casos, se identifican rasgos culturales expresados en bienes o prácticas culturales que no obedecen a estos discursos, sino a una dinámica local apropiada por la sociedad que, de inicio, no tiene un fin económico-turístico, pero sí una vía de identidad y diferenciación respecto de otros estados de la república, incluso, grupos sociales dentro del mismo estado de Oaxaca.
} 
matlacihua", entre otros personajes importantes de la cultura mexicana. Con la finalidad de que el lector entienda su dinámica, a continuación mostramos una descripción de una comparsa.

El $1^{\circ}$ de noviembre de 2018 en la colonia Cinco Señores, en la ciudad de Oaxaca, alrededor de las 11:00 pm empezamos a seguir una comparsa conformada por un centenar de pobladores de esta colonia disfrazados, y que estaba encabezada por una banda de música popular. En las calles que recorría toda esta aglomeración algunos comercios, cenadurías y tiendas de conveniencia estaban abiertos. Algunos comensales y mucha gente que, como nosotros, seguía la comparsa escuchábamos la música de banda y veíamos a la gente disfrazada bailar al ritmo de la música.

El ambiente era muy semejante al de un carnaval, pero en lugar de carros alegóricos se encontraban en el escenario de fiesta un par de marmotas $^{15}$ y varios monos de calenda. Los disfraces de las personas que participan, que por costumbre son exclusivamente hombres, no era sólo de catrinas; había gente disfrazada de Donald Trump, del aún mandatario mexicano, Enrique Peña Nieto, máscaras de luchadores o monstruos clásicos del cine hollywoodense, lo que torna muy interesante el evento, pues a través de la parodia y el ambiente de fiesta existe una crítica política y ridiculización de los líderes nacionales e internacionales.

También se veían disfraces de personajes mexicanos legendarios como Pedro Infante, Tintán o Cantinflas que forman parte de la historia del cine mexicano de los años cuarenta y cincuenta, así como disfraces de seductoras mujeres apache, catrinas y queers que manifiestan la característica de estos espacios en los que existe una relación con la comunidad LGBT+ que contrasta con otras zonas del país y una apropiación de la comparsa por esta comunidad.

Los disfraces son esenciales en este evento y se invierte mucho tiempo y dinero en éstos, como menciona una habitante de la zona, con el fin de concursar "porque al mejor disfraz les dan un premio y así se motiva a los jóvenes a continuar con la tradición [...] La comparsa. Va pasando por las casas y donde se detengan a bailar con la banda, los monos de calenda y todo, la gente de sus ofrendas les regala fruta, chocolate, mezcal, café, tamales... lo que tengan, y lo van echando en una cesta o pizcador" (Entrevista Hilda Hernández Ochoa, 3 de noviembre de 2018).

Esta representación describe una dinámica de interacción social en la comunidad, incluso con otras comunidades, pues también participan habitantes de otros barrios. En cambio, la presencia de turistas es casi nula y tampoco existe ningún tipo de promoción del Estado sobre este evento. Cinco Señores es una colonia popular, relativamente nueva si se compara con otros barrios de la ciudad. Sin embargo, entre los oaxaqueños la comparsa de este lugar goza de prestigio.

\footnotetext{
15 La marmota es un elemento tradicional presente en los bailes oaxaqueños de la zona de los Valles Centrales, compuesta por un poste largo de más de dos metros de longitud que se conoce como espiga, y en la punta una estructura compuesta por doce costillas que forman el esqueleto de una esfera, la cual está forrada con tela y adornada con trozos de tela de diversos colores o, en algunos casos, con imágenes. Esta estructura gigante que semeja una suerte de paleta de caramelo, se le da vueltas y se mueve al ritmo de la música, en este caso de la comparsa, pero es muy utilizada en cualquier evento como al término de la celebración religiosa de una boda que acompañada de la banda y las bailarinas vestidas de traje típico siguen a los novios y a su familia al lugar de la fiesta.
} 


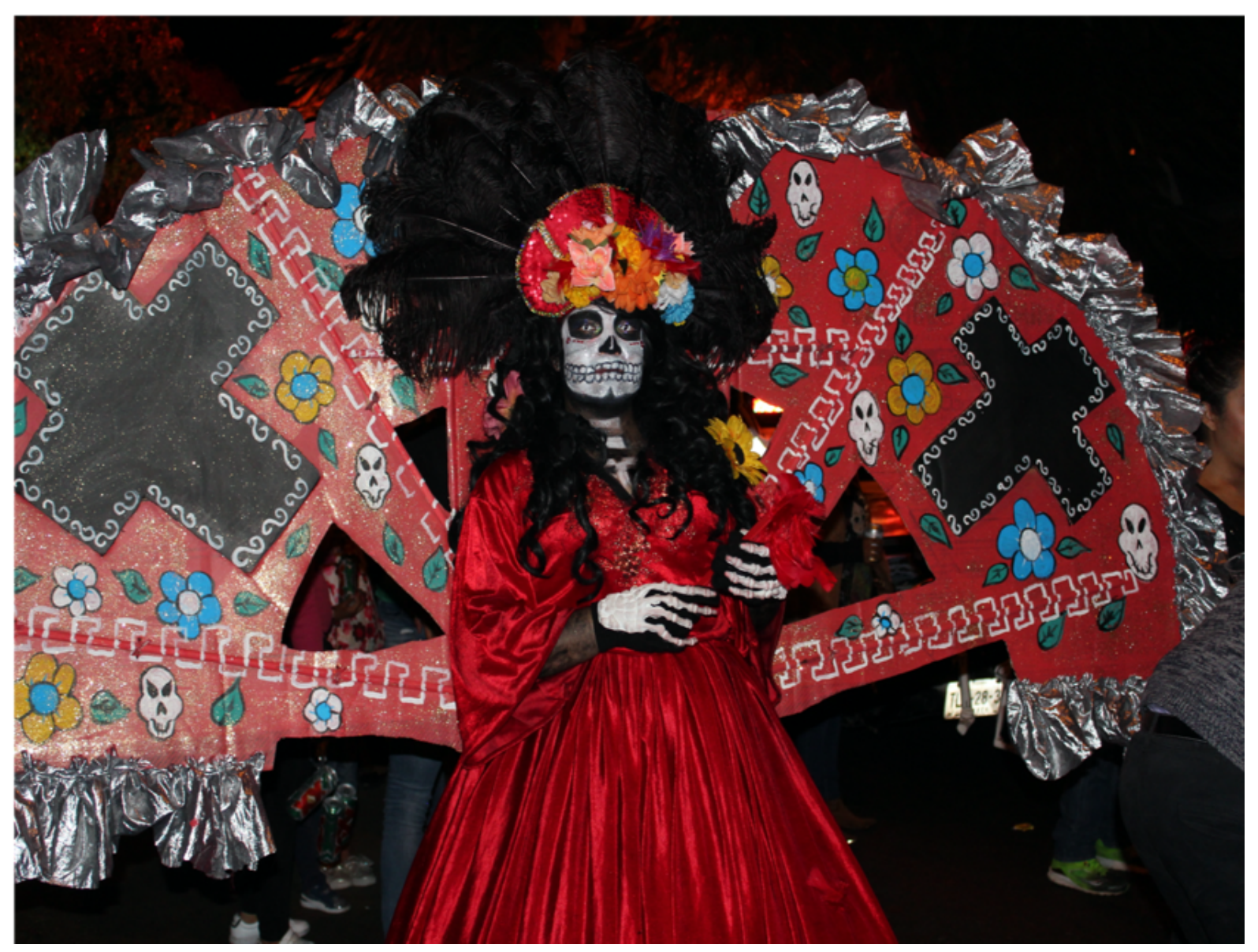

Imagen 1. Hombre disfrazado de catrina en la comparsa de la agencia de Cinco Señores. Fotografía por Jorge Valtierra Zamudio, 2018.

De esta forma, se presenta un ejemplo de patrimonio local y vivencial en el que, en el entendido de que la cultura no es estática, las comparsas incluyen grupos sociales, crítica y parodia política y una manifestación de la muerte como fiesta y no como terror, así como un escenario compartido entre gente conocida y no conocida de camaradería y música.

Las dinámicas de las fiestas son un rasgo importante de la identidad de los oaxaqueños. Es claro que representaciones ya tradicionales como la comparsa llaman la atención de sectores ajenos al grupo cultural que desempeña estas actividades. La tendencia en las comparsas, sobre todo aquellas de barrios famosos por tradición como Xochimilco o Jalatlaco con mayor afluencia turística, es que haya una presencia importante de extranjeros y que el contexto se modifique y se promueva por la Secretaría de Turismo para generar un espectáculo que, ciertamente, puede modificar y folclorizar estas costumbres.

En otro ejemplo con base en información etnográfica, el 1 de noviembre de 2018 y 2019 en el barrio de Xochimilco en Oaxaca, se observó una participación muy activa de diversos turistas extranjeros. En particular, en la escena etnográfica que se expondrá a continuación predominaba la presencia de jóvenes estadounidenses maquillados de catrinas y catrines, y disfrutaban, a la par de consumir altas cantidades de alcohol, las comparsas y la visita a los panteones municipales al ritmo de las bandas musicales oaxaqueñas. 


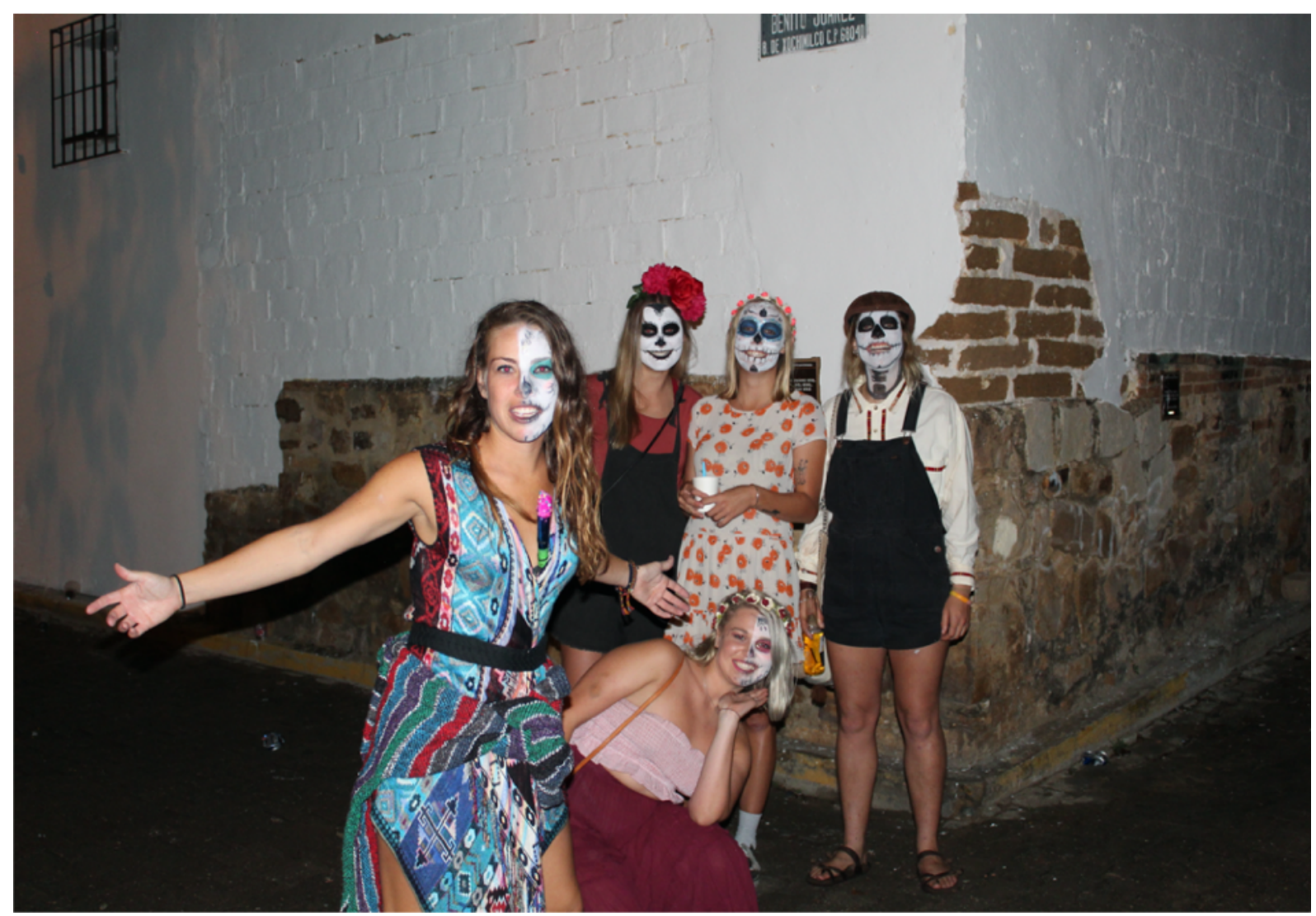

Imagen 2. Turistas estadounidenses en el barrio de Xochimilco.

Fotografía por Jorge Valtierra Zamudio, 2019.

En este barrio de origen prehispánico las casas estaban adornadas con calaveras, había maniquíes vestidos de catrinas a la mitad de la acera para dar otro ambiente, las casas estaban abiertas para que la gente pasara y viera las tradicionales ofrendas que son impactantes y muy apegadas a la tradición.

Ese día, paseando por las calles adornadas con motivos del Día de Muertos, nos dirigíamos al panteón. La decoración de este lugar destacaba por sus colores otoñales a partir de la flor anaranjada de cempasúchil y una gran cantidad de veladoras encendidas dispuestas sobre las criptas y lápidas, en las que los familiares, sentados alrededor de la tumba acompañaban al difunto con comida y mezcal; y alguno con una guitarra tocaba algunas canciones que quizá en vida le gustaban al finado.

La actitud de la gente en este contexto era como una reunión en casa, contando chistes, anécdotas relacionadas con el familiar que yacía en la tumba y constantemente brindando en su honor con mezcal o aguardiente. Esta escena se repite en muchos puntos del panteón, aunque hay otras tumbas que están solitarias y oscuras, a través de las que se observa uno que otro turista leyendo los epitafios, y luego pasan a las tumbas donde se encuentran los familiares del difunto reunidos pero sin interactuar con ellos (Notas de campo, 01 de noviembre de 2019).

Es interesante, a pesar de las características del lugar con su escenario colorido en plena noche, la forma en que los turistas extranjeros, sin intentar quizá comprender el símbolo de estas prácticas llevadas a cabo por los pobladores, ya acostumbrados a la presencia de turistas en estas 
fechas, perciben el exotismo que esto representa en contraste con su cultura y viven una experiencia muy similar a lo que la intelectualidad mexicana desde la década de 1930 legó y difundió al mundo, otorgando características místicas prehispánicas a estas prácticas. ${ }^{16}$

Sin embargo, pese a la aparente carencia de interacción entre los turistas y los locales, sí se observa una intersección entre lo folclórico y espectacular con una tradición que viene de varias generaciones atrás, y si bien no todos los locales aprovechan la presencia y derrama económica de los turistas, no tienen problema con esto, pues saben que representa un beneficio económico para su ciudad.

Un hecho más que destaca es que buena parte del ambiente que muchos extranjeros seguramente percibieron y/o que buscaban, obedecía a una imagen globalizada de esta festividad con base en la industria cinematográfica y otros medios de comunicación. Sobre esto, algunos turistas a los que se pudo entrevistar, ya terminadas las festividades, comentaban:

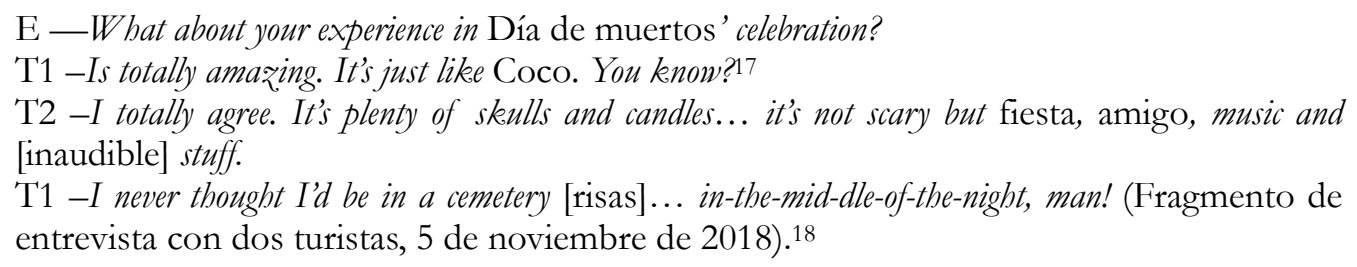

Una festividad de esta naturaleza representa-además de un espectáculo para muchos foráneos muy distinto a las tradiciones globalizadas, como el halloween, en especial para los estadounidenses - un aspecto muy característico de México, y en particular de Oaxaca, a saber: la dinámica de 'compartir', de romper con una serie de diferencias que aíslan e individualizan a las sociedades modernas.

El quid es que la dinamicidad de la cultura; es decir, la constante transformación de las representaciones culturales oaxaqueñas, también se van globalizando y, en muchos casos, terminan en una suerte de reinvención de las tradiciones para satisfacer a un mercado turístico. Algunas de las comparsas, sobre todo las más promocionadas por el Estado, se han folclorizado, se presentan con elementos recreados y vistos en ciertos filmes como la reciente producción de Coco y atraen una gran cantidad de extranjeros que se pintan el rostro de calaveras y asisten a eventos de luz y sonido con coreografías contemporáneas, vestuario y música también

\footnotetext{
16 Entre las aportaciones de la intelectualidad mexicana se tiene el ejemplo de la fiesta de estas fechas como expresa Octavio Paz, incluyendo la fiesta en relación con el horror. Octavio Paz advierte: "la contemplación del horror, y aun la familiaridad y la complacencia en su trato, constituyen contrariamente uno de los rasgos más notables del carácter mexicano. Los cristos ensangrentados de las iglesias pueblerinas, el humor macabro de ciertos encabezados en los diarios, los "velorios", la costumbre de comer el 2 de noviembre panes y dulces que fingen huesos y calaveras, son hábitos, heredados de indios y españoles, inseparables de nuestro ser. Nuestro culto a la muerte es culto a la vida, del mismo modo que el amor, que es hambre de vida, es anhelo de muerte" (Paz, 1994: 26).

17 Alude a la película estadounidense dirigida por Lee Unkrich, producida por Pixar y distribuida por Walt Disney Pictures, sobre una historia mezclada, con elementos supuestamente tradicionales, pero muy recreados, folclorizados y, si vale el adjetivo, disneylandizados en relación con la idea de la muerte en México y el Día de los Fieles Difuntos.

${ }^{18}$ Los dos turistas extranjeros entrevistas venían de Wisconsin, EUA. y Skåne, Suecia, en el Aeropuerto Internacional de Oaxaca en Xoxocotlán, Oax., el 5 de noviembre de 2018. Las siglas corresponden a E (entrevistador), T1 (turista 1sueco) y T2 (turista 2 estadounidense).
} 
folclorizados como las representaciones de artistas como Lila Downs o Susana Harp. ${ }^{19}$ Esto contrasta con otras comparsas que sin estar ajenas a elementos exógenos e importados que se observan en los disfraces, conservan una dinámica del barrio mismo, con características más populares que no se promueven para la satisfacción de un mercado turístico, sino local.

La noción de patrimonio cultural intangible en este tipo de "eventos culturales" se traduce en actos espectaculares como ocurre en otros "eventos" de gran tradición y reconocimiento como la Guelaguetza. Sin embargo, esta concepción del patrimonio cultural oculta otros elementos que están involucrados en este ambiente festivo, como la organización misma entre los locales para administrar la comparsa, contratar la música de banda, invitar a la colonia o barrio a participar de la fiesta, etc.

Esto también puede observarse en las ofrendas de muertos que se localizan en un ámbito más privado, el contexto ritual y cultual que se observa en los templos, en la visita al panteón de zonas no tan folclorizadas como Xoxocotlán, ${ }^{20}$ la preparación de alimentos tradicionales para cenar en la tumba del familiar difunto en compañía de toda la familia, brindar con mezcal, el uso de copal y velas, además de los adornos con flores tan importantes en esta época como el cempasúchil y la flor inmortal, entre muchos otros elementos, son características que tienen otra valoración, como ya se expuso arriba en la descripción del panteón de Xochimilco.

Ciertamente, todo esto forma parte del patrimonio, pero no está contemplado en las producciones cinematográficas que forjan una imagen de la cultura oaxaqueña a nivel mundial. Se tata de lo que Prats concibe como patrimonio localizado y/o local; es decir, en "[...] el ámbito local, por decirlo así, lo ideológico se torna vivencial y adquiere en consecuencia, un carácter infinitamente más complejo. Entramos en el campo de la interpretación subjetiva (o intersubjetiva si es compartida) [...], [la cual] se basa en la memoria" (Prats, 2005: 7), una memoria que no tiene el foráneo o la imagen global creada sobre el día de muertos mexicano. Un ejemplo importante de este tipo de patrimonio local, además de lo expresado en la comparsa de Cinco Señores, se ilustra en el registro etnográfico realizado en la localidad de San Antonino Castillo Velasco.

Entre las características de esta población de origen zapoteca cercana a la ciudad de Oaxaca, está el bordado de blusas y el arte culinario a través de las tradicionales empanadas. Sin embargo, San Antonino también destaca por su población de floricultores, quienes también presentan dotes artesanales que vienen de mucho tiempo atrás y que, entre otras cosas, utilizan las flores para crear figuras que entran en concursos, incluso en la ciudad de Oaxaca como la tradicional "noche de rábanos del 23 de diciembre". ${ }^{21}$

\footnotetext{
19 Se trata de cantantes de música folk mexicana muy representativas por combinar elementos modernos a canciones tradicionales y con un vestuario tradicional, pero muy estilizado y muy distinto al que en la realidad visten las muejres indígenas en Oaxaca.

20 A diferencia de Xochimilco que se ha ido habitando cada vez más por extranjeros, sobre todo estadounidenses jubilados, Xoxocotlán es un gran municipio que se conforma por gente de un sector más bien popular.

21 La tradicional noche de rábanos es una festividad que se celebra el 23 de diciembre, donde hortelanos y floricultores participan con figuras y diseños, no necesariamente navideños, pero sí relacionados con elementos propios de la región, utilizando materiales como rábanos, totomoxtle (hoja que envuelve la mazorca del maíz) y flor inmortal, también conocida como siempreviva (Helichrysum Bracteatum). Los artesanos concursan con las figuras que crean con estos materiales obteniendo premios diversos.
} 
El uso de la flor, en especial la llamada flor inmortal o 'siempreviva', en estas fechas de Día de Muertos y de Responso se manifiesta el día 3 de noviembre, en que los pobladores van al panteón para adornar las tumbas de los difuntos con estas flores, con diversas figuras no necesariamente sacras. $^{22}$

El 3 de noviembre de 2018, al llegar a esta población, pretendíamos visitar al artista plástico Alfonso Canseco y a su padre que es artesano y floricultor. Ese día nos llevaron a visitar el panteón para mostrarnos cómo se adornan las tumbas con flor inmortal. De camino nos platicaba Alfonso que desde hacía mucho tiempo que la gente, no necesariamente artesanos, en ese día de responso, competía por el mejor adorno de la tumba con la flor que como familia cultivaban. Esto significa ganar más prestigio como floricultor. Sin embargo, a él por tener ya una licenciatura en artes plásticas no lo dejan concursar debido a que posee una ventaja sobre el resto de los concursantes (Notas de campo, 3 de noviembre de 2018 en San Antonino Castillo Velasco, Oaxaca).

Al llegar al panteón, a las afueras de éste había una gran cantidad de puestos de comida, en especial de las tradicionales empanadas del pueblo, así como una exhibición de blusas bordadas. El flujo de personas era excesivo y más al interior del cementerio. Pero muchas de estas personas eran de la ciudad de Oaxaca, algunos artesanos de otras localidades, fotógrafos, también percibimos algunos antropólogos, pero la mayoría de la gente eran pobladores de San Antonino.

$\mathrm{Al}$ interior del panteón, se observaban tumbas con decoraciones de flor inmortal con sus característicos colores purpúreos, carmines y anaranjados (Véase imagen 3). Las tumbas decoradas más valiosas, decía Alfonso Canseco, son aquellas que aún no tienen lápida de piedra, sino aquellas en las que "está sólo la tierra que se puede manejar y moldear, y es con ésta que se hace la decoración y a la que se agregan las flores" (Conversación personal 3 de noviembre de 2018 en San Antonio Castillo Velasco, Oaxaca). ${ }^{23}$

Era difícil moverse en el cementerio, pues había mucha gente que va viendo cada tumba decorada, además de fotógrafos y los jueces que iban calificando a los concursantes. Sin embargo, en esta multitud y este escenario que contrasta con otros puntos de Oaxaca más turísticos, si se mira la práctica y símbolo que hay detrás de esto en una suerte de mirada estereográfica (Escalona, 2016), el prestigio no sólo se muestra en la decoración de la tumba, sino en el hecho de que se decora con flores que se fueron cuidando desde su siembra hasta su cosecha por los floricultores de cada familia, lo que implica una labor de organización muy especial entre cada uno de los miembros de la familia, un costo e inversión considerables, pues no son flores baratas,

\footnotetext{
22 El artista plástico, Alfonso Canseco, oriundo de esta localidad, explica que las tumbas se decoraban antes con motivos religiosos, ya sea la escena de la vida de un santo, el 'Sagrado Corazón', etcétera (Conversación personal 3 de noviembre de 2018 en San Antonino Castillo Velasco, Oaxaca).

23 Además de lo que expresa Canseco al respecto, y que se refiere a la presencia de las lápidas como parte de la modernidad, también explica que las características de la población se han ido transformando, pues ahora hay una mayor presencia de artistas que no se les permite participar por esa condición, dejando el espacio sólo para los artesanos o los pobladores sin estas habilidades plásticas. (Conversación personal el 3 de noviembre de 2018 en San Antonino Castillo Velasco).
} 
además de la pericia y habilidad del floricultor para usar ese material y hacer un diseño original de lo que va a decorar.

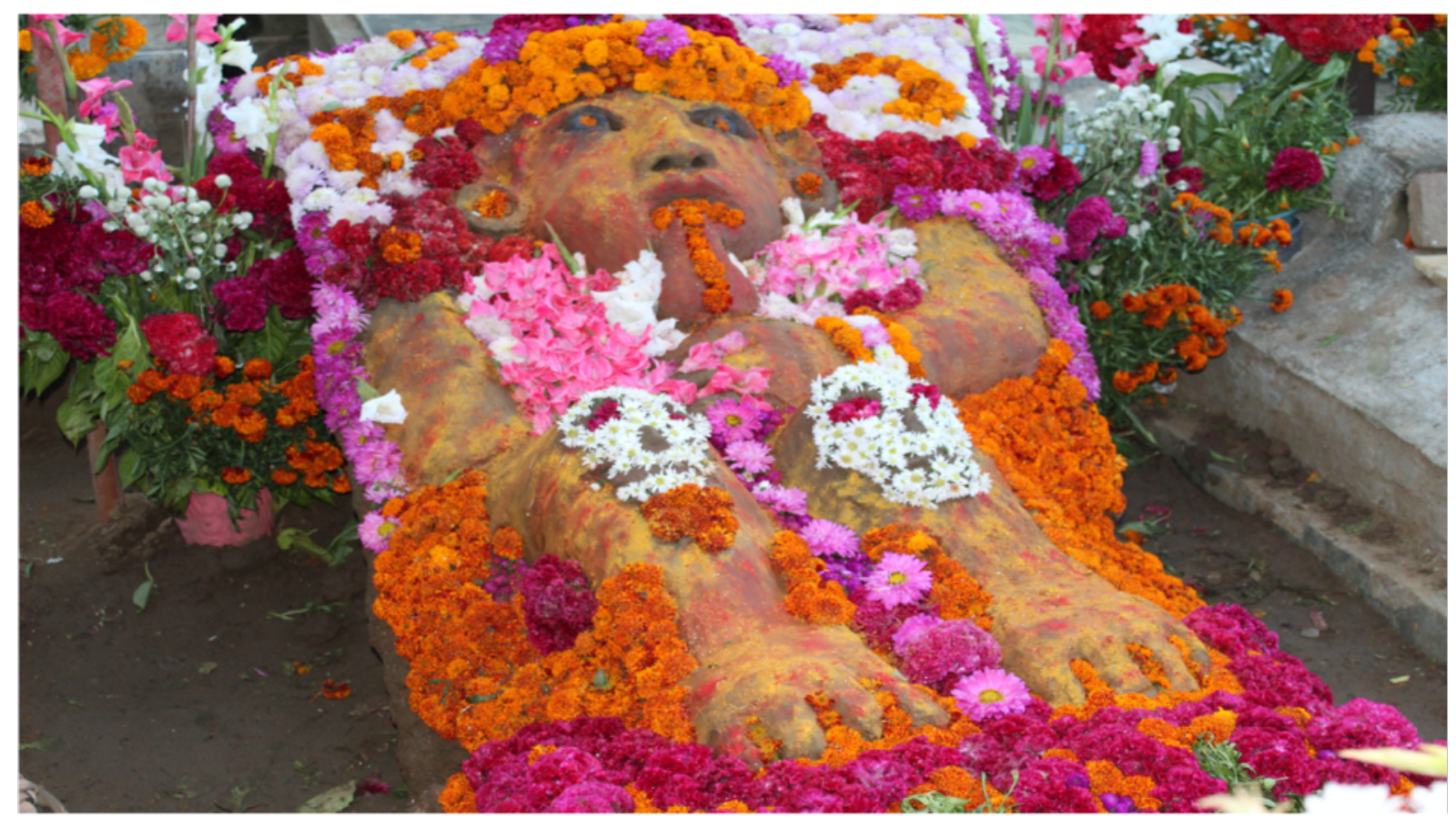

Imagen 3. Tumba decorada con flor inmortal en San Antonio Castillo Velasco.

Como puede observarse, se trata de una práctica que, a pesar de la cantidad de visitantes foráneos, es propia de la comunidad y que no es muy promovida por el estado. La afluencia turística a este pueblo se da principalmente por los bordados y no por estas prácticas culturales. Pero es claro también que la presencia de la gente que visita la comunidad, si se le concibe como turista, también participa de una derrama económica para los comercios que están establecidos fuera del cementerio, por lo que ajenos a la naturaleza simbólica y el patrimonio local y vivencial de la decoración de tumbas, participa de una forma de folclorización del pueblo que se expresa en los bordados.

La transformación sociocultural de esta población no sólo reafirma la dinamicidad de la cultura, sino que a pesar de esos cambios, es la práctica misma de la decoración de las tumbas con una flor que se cultiva durante el año que es producto del esfuerzo, organización, transmisión de saberes culturales de generación en generación en el cultivo de la flor inmortal y la decoración de tumbas, la transmisión y apropiación de significados y símbolos en esta práctica cultural, entre muchos otros aspectos, lo que hace que esta tradición sea patrimoniable.

A pesar de su riqueza cultural esta serie de prácticas no son consideradas como patrimonio cultural en el marco de una visión folclorizada y, por tanto, no son consideradas al momento de establecer políticas para garantizar los derechos culturales. Aunque en esta tradición comunitaria se perciben elementos que hablan de un patrimonio local, en términos de Prats, no posee las 
características requeridas por el mercado como para otorgarle una categoría de patrimonio cultural que pueda ser usada para satisfacer al sector turístico. ${ }^{24}$

En este orden de ideas, el caso de San Antonino y su tradicional uso de la flor inmortal para la decoración de tumbas, entre otras prácticas artesanales, alude más a una dinámica comunitaria, a la valoración del trabajo de la floricultura que no sólo representa el sustento económico de la comunidad, sino que se destina un tiempo y saberes de generaciones atrás en la creación y uso de ese producto en la decoración de tumbas el 3 de noviembre de cada año, y la valoración comunitaria de las flores y diseños de esas decoraciones con una carga simbólica.

Lo que también es perceptible es que la práctica y reproductibilidad de esta tradición empieza a ser cada vez más conocida, aunque no promovida por el estado como tal; pero sí se ve una mayor presencia de foráneos que quiere ver el panteón, con las tumbas decoradas que entran en concurso. De ahí el interés en esta práctica que incide en un flujo de visitantes cada vez mayor, pero que no se hace o no atiende a ese público exógeno, mucho menos a un mercado turístico en forma, como en la ciudad de Oaxaca.

\section{CONSIDERACIONES FINALES}

En este texto hemos retomado información de una serie de prácticas etnográficas que nos han permitido identificar actitudes y dinámicas socioculturales en torno al Día de Muertos en Oaxaca. Hemos constatado que las instituciones, los modelos mercantiles y la perspectiva globales se orientan a una concepción del patrimonio cultural que contrasta con las perspectivas locales y cotidianas.

No es sorpresivo identificar cómo la transformación de ciertas prácticas y la generación de un ambiente artificial en el que se hiperbolizan y se destacan rasgos propios del día de muertos para satisfacción de un público visitante y turístico, ha sido aprovechado para la economía principal de la zona del Valle de Oaxaca, al punto de significar una derrama económica de la que viven los habitantes de la ciudad buena parte del año.

A diferencia de otros años, la promoción que se hizo de estas fechas en el 2018 y 2019 al exterior y el aprovechamiento de una imagen muy atractiva del día de muertos a través de filmes como Coco de Pixar, la concurrencia de extranjeros y visitantes de otros estados de la república a Oaxaca fue inusual.

\footnotetext{
24 Ahora bien, existen dos aspectos a considerar. El primero ha sido planteado por el antropólogo Jorge HernándezDíaz sobre la clasificación o categorización de una práctica o bien cultural a partir de las leyes del mercado y las leyes del poder; es decir, el papel del Estado en la promoción de estas prácticas o productos artesanales, así como su comercialización. Al final, esta forma de patrimonio cultural conlleva elementos necesarios para ser valorada como tal, pues "la situación mercantil de un objeto consiste en el traslape del contexto, la cultura y las condiciones sociales [...] mercancías que son producidas en diversos contextos culturales, algunos de ellos subordinados al sector hegemónico" (Hernández-Díaz, 2016: 51). El caso de San Antonino Castillo Velasco, sin embargo, no es éste; por lo menos no aún. Llorenç Prats alude a dinámicas como las del caso que se expone, "cuyo interés trasciende su ubicación y [es] capaz de provocar por sí mismo flujos de visitantes con relativa independencia de la misma" (Prats, 2005: 24).
} 
Aunque, como mencionamos, la cultura no es estática y estas manifestaciones son resultado de su propio dinamismo, la reducción de nuestra concepción del patrimonio cultural a prácticas orientadas al mercado global tiende a invisibilizar lo que ocurre nivel local. Esto se debe a la apropiación por parte de una sociedad de una práctica o bien, la herencia de saberes, los rasgos como la cosmovisión, los símbolos y significados de la práctica o bien que definen el patrimonio y no el mercado.

Sin oponerse a una actividad económica basada en el turismo y la venta de piezas artesanales más estilizadas para satisfacer un mercado que consiste en la compra de 'arte popular' y de la que dependen familias y empresarios en Oaxaca, sí es importante establecer que se trata de otro tipo de cultura; es decir, es más una cultura global que se observa en un fenómeno de integración y/o mezcla de rasgos y elementos culturales que conviven y coexisten, en una suerte de cultura híbrida. 25

Sin embargo, debe también considerarse que lo que definimos como cultura alude a prácticas, costumbres, memoria, herencia, cosmovisión, entre otros aspectos que no están incluidos ni discernidos en esa cultura global. Eso también es patrimonio cultural para un pueblo. En tanto siga pensándose y definiendo el patrimonio cultural desde una perspectiva mercantil, artificiosa y determinada desde estructuras hegemónicas como el Estado y organismos nacionales e internacionales, se corre el peligro de afianzar la exclusión y la falta de reconocimiento de la diversidad cultural en el país.

La consecuencia de no reconocer la legitimidad cultural de las prácticas que no están orientadas al mercado es la incomprensión de la complejidad y la pluralidad social. En México existe un alto grado de discriminación, marginación y exclusión de las minorías étnicas. Entre otros motivos, esto es fruto de la incomprensión de estos grupos culturales, lo que se observa en estereotipos, prejuicios y estigmas. Aunque la cultura de estos grupos es vivida y reproducida de manera cotidiana, corre peligro de desplazarse para poder ajustarse y resignificarse en las culturas dominantes y globalizadas como una forma de supervivencia. ${ }^{26}$

El reconocimiento de los derechos culturales debería garantizar la continuidad de las prácticas, los símbolos y la memoria de estos grupos sociales, sin embargo, cuando se parte de una concepción selectiva del patrimonio cultural incluso puede favorecer su desplazamiento y su invisibilidad. De ahí la importancia de ampliar nuestra concepción del patrimonio cultural como elemento necesario para un reconocimiento real de los derechos culturales.

\footnotetext{
25 García Canclini se refiere con este término de hibridación como una serie de "procesos socioculturales en los que estructuras o prácticas discretas, que existían en forma separada, se combinan para generar nuevas estructuras, objetos y práctcas" (García Canclini, 2016: III) como el spanglish, la hibridación de gastronomías de orígenes distintos, fusiones artísticas y literarias, etc.

$26 \mathrm{Al}$ respecto, la antropóloga Maya Lorena López advierte que los alcances de los derechos culturales con base en lo que interpreta por cultura no reconoce otras dimensiones de la cultura, incluso, se tiene la impresión de que el acceso a la cultura significa acceder a lo que se concibe como patrimonio cultural sin reconoer otras manifestaciones. Es por ello que se piensa que el patrimonio cultural, además de ser una forma de definir qué sí es y que no es cultura, implica un ejercicio en el que no se reconoce "la capacidad de gestión de los sujetos para definir [cultura] y salvaguardarla" (Pérez, 2018: 426).
} 
BIBLIOGRAFÍA

BAZANTE, Violeta (ed.). "Manual de procesamiento documental de para colecciones de patrimonio cultural”. UNESDOC (2008).

BENJAMIN, Walter (2015). La obra de arte en la era de su reproductibilidad técnica y otros textos. Buenos Aires: Ediciones Godot.

BRANDES, Stanley. "El Día de Muertos, el Halloween y la búsqueda de una identidad nacional mexicana". Alteridades. No 10 (20) (2000): 7-20.

Castellanos-Arenas, Mariano (2014). El patrimonio cultural territorial. Paisaje, historia y gestión. Ciudad de México: Ediciones E y C-BUAP-ADABI.

CDESC. "Observación General No. 21. Trato humano de las personas privadas de libertad (artículo 10)”, Observaciones Generales Aprobadas por el Comité de Derechos Humanos (1992).

DeClaración De Friburgo. "Los derechos culturales. Declaración de Friburgo. Los derechos culturales”. Cultural Rights.net (2007).

Eagleton, Terry (2018). Culture. Reino Unido: Yale University Press.

ESCALONA, José Luis. "Etnomercancía y sobrefetichización. Ensayo de mirada estereográfica". Relaciones. Estudios de Historia y Sociedad. No 148 (2016): 259-288.

GarCía CANCLINI, Néstor (2016). Culturas hibridas. Estrategias para entrar y salir de la modernidad. Ciudad de México: Debolsillo.

GARCÍA CANCLINI, Néstor (2006). "¿Cómo se comporta la sociedad mexicana ante la globalización cultural?” Arizpe, Lourdes (ed.). Retos culturales de México frente a la globalización, Ciudad de México: Cámara de Diputados LIX Legislatura-M.A. Porrúa: 55-92.

García Godoy, Juanita. (1998). Digging the Days of the Death: A Reading of Mexico's Dias de Muertos. Denver: University Press of Colorado.

GEERTZ, Clifford (1987). La interpretación de las culturas. Ciudad de México: Editorial Gedisa.

GonZÁlez-VAras, Ignacio (2015). Patrimonio cultural. Conceptos, debates y problemas. Madrid: Cátedra, 2015.

HERnÁNDEZ-DíAZ, Jorge (2016). Artesanías. Urdiendo identidades y patrimonios para el mercado. Oaxaca de Juárez: Instituto de Investigaciones Sociológicas-Universidad Autónoma "Benito Juárez" de Oaxaca-Juan Pablos.

Hiriart Pardo, Carlos Alberto (2006). "Noche de muertos en Michoacán. Reflexiones sobre su manejo como recurso turístico cultural”. Romero Rojas, Óscar (ed.). La festividad indígena dedicada a los muertos en México. Patrimonio cultural y turismo. Cuadernos 16. Ciudad de México: Conaculta: 124-131.

HobsBawm, Erich \& RANGER, Terrence (2012). La invención de la tradición. Barcelona: Crítica.

Lasso Prado, Aída; Prado Lasso, Édison \& Paredes giraldo, Holbein. "Revisión del concepto de derechos culturales". Criterio Libre Jurídico. No. 16(1) (2019): 4-13. 
MALVIDO, Elsa (2006). "La festividad de todos santos, fieles difuntos y su altar de muertos en México. Patrimonio intangible de la humanidad”. Romero Rojas, Óscar (ed.). La festividad indígena dedicada a los muertos en México. Patrimonio cultural y turismo. Cuadernos 16. Ciudad de México: Conaculta: 41-55.

LIZAMA, Jesús (2006). La Guelaguetza en Oaxaca. Fiesta, relaciones interétnicas y procesos de construcción simbólica en el contexto urbano. Ciudad de México: Centro de Investigaciones y Estudios Superiores en Antropología Social.

PAZ, Octavio (1994). El laberinto de la soledad. Ciudad de México: Fondo de Cultura Económica.

PÉREZ Ruiz, Maya Lorena. "Reseña de Ley General de Cultura y Derechos Culturales Promulgada en México en 2017”. Revista cultura y representaciones sociales. N. 12(24) (2018): 425-431.

PIDESC. "Pacto Internacional de Derechos Económicos, Sociales y Culturales, y su protocolo Facultativo" cndh.org.mx. (2012).

PRATS, Llorenç. “Concepto y gestión del patrimonio local”. Cuadernos de Antropología Social. N 21 (2005): 17-35.

Rosas MANTECón, Ana (2006). "Turismo y patrimonio: realidades y espejismos de una promesa." Arizpe, Lourdes (ed.). Retos culturales de México frente a la globalización. Ciudad de México: Cámara de Diputados LIX Legislatura-M.A. Porrúa: 473-497.

SECtur. "Pueblos mágicos" Secretaría de Turismo. Gobierno de México (2014).

UNESCO. "Unesco Cultura for Development Indicators". UNESDOC Biblioteca digital (2014). 